\title{
Communication \\ Functional Compounds from Banana Peel Used to Decrease Oxidative Stress Effects
}

\author{
Ionela Avram $^{1}$ (D), Florentina Gatea ${ }^{2}$ (D) and Emanuel Vamanu ${ }^{3, *(\mathbb{D})}$ \\ 1 Department of Genetics, University of Bucharest, 36-46 Bd. M. Kogalniceanu, 5th District, 050107 Bucharest, \\ Romania; ionela24avram@yahoo.com \\ 2 Centre of Bioanalysis, National Institute for Biological Sciences, 296 Spl. Independentei, 060031 Bucharest, \\ Romania; flori_g_alexia@yahoo.com \\ 3 Faculty of Biotechnology, University of Agricultural Sciences and Veterinary Medicine, \\ 011464 Bucharest, Romania \\ * Correspondence: email@emanuelvamanu.ro; Tel.: +40-742-218-240
}

Citation: Avram, I.; Gatea, F.;

Vamanu, E. Functional Compounds from Banana Peel Used to Decrease Oxidative Stress Effects. Processes 2022, 10, 248. https://doi.org/ $10.3390 /$ pr10020248

Academic Editor: Bruna de Falco

Received: 21 December 2021

Accepted: 24 January 2022

Published: 27 January 2022

Publisher's Note: MDPI stays neutral with regard to jurisdictional claims in published maps and institutional affiliations.

Copyright: (C) 2022 by the authors. Licensee MDPI, Basel, Switzerland. This article is an open access article distributed under the terms and conditions of the Creative Commons Attribution (CC BY) license (https:// creativecommons.org/licenses/by/ $4.0 /)$.

\begin{abstract}
Banana peel, a little-used waste, contains a high amount of biologically active compounds. The aim of the study is to demonstrate in vitro, the antioxidant, cytotoxic, and antimicrobial effects of hydroalcoholic extracts from yellow (BP) and red (BPR) banana peels. The analysis of the extracts by Capillary Zone Electrophoresis (CZE) has confirmed the presence of several bioactive compounds. BPR has a higher in vitro antioxidant activity than BP, which correlates with a significant cytotoxic, antimicrobial effect, with a UVA/UVB rate of 0.9 . In the case of BPR, the results confirm the presence of isoquercitrin and kaempferol in a 1:3 ratio. The bioactive compounds from the extracts have shown a different interaction with HCT-8 cell lines and with tested bacterial strains with pathogenic properties. The HCA analysis proved the biological value of BPR to reduce oxidative stress and its potential use in natural products.
\end{abstract}

Keywords: in vitro; cytotoxicity; kaempferol; antimicrobial

\section{Introduction}

Byproducts (banana peel) are an important source of functional compounds that can be harnessed due to their antioxidant, anti-inflammatory, cytotoxic, and antimicrobial properties [1]. Alternative sources can be identified and characterized, ensuring the sustainable use of resources in a circular economy These effects that have been attributed to the functional compounds depend on the bioavailability of these compounds. In the current climatic context, the increase of UVB radiation causes an increasingly pronounced oxidative pressure in keratinocytes [2]. Polyphenolic compounds have been shown to reduce the risk of increased oxidative stress and are thus sought after to reduce the secondary risks of prolonged exposure to UVB radiation [3]. They help in reducing cytotoxicity targets in these studies that correlate the antioxidant action with the SPF index's value.

The use of food waste in the extractive recovery of compounds of interest to the biopharmaceutical and cosmetics industry is an innovative way of identifying valuable substrates. This choice was determined by the presence of many functional compounds [4]. In the case of banana peels and other valuable substances, such as pectin, they could be isolated by microwave-assisted extraction. Thus, the pectin obtained was used as a stabilizing agent in the food industry and demonstrated a functional role by normalizing digestive processes [5]. Other biotechnological uses of banana peel are to obtain protein for farm animal nutrition, bioethanol, or enzyme isolation [6]. These are the main industrial uses of banana peel, traditionally.

The use of alternative sources of biologically active compounds by multiple pharmaceutical and cosmetic industries has led to the development of new products. Many current products include previously untapped sources, which are obtained from food 
industry waste [6]. The recovery of this waste was based on its functional properties, which led to an increase in antioxidant status. Banana peels extract has such use in reducing oxidative stress, a major cause of many chronic diseases [7]. In direct relation with the characterization of the biological effect and the phytochemical profile [8], will determine the procurement of competitive products that help increase the products' efficacy [9]. That may include biopharmaceutical compounds integrated into the cosmetic products [10]. This study aims to characterize the yellow and red banana peel extracts available in the Romanian market. These were phytochemically described as cytotoxic, antioxidant, and antimicrobial, with anti-UVB effects demonstrated.

\section{Materials and Methods}

\subsection{Samples}

Banana peels (yellow -BP and red -BPR) were collected and frozen until used. The samples (100 g) were mixed with 50\% ethanol (1:20 g/v) and kept for a maximum of $48 \mathrm{~h}$ in the dark. Next, the mixture was filtered under a vacuum. The final solution was preserved in dark bottles [11].

\subsection{Antioxidant Activities Determination-In Vitro}

Two methods were used for in vitro antioxidant characterization: DPPH (2,2-Diphenyl1-picrylhydrazyl) radical scavenging activity [12] and reducing power [13]. Ascorbic acid (AA) and TBHQ (Tert-butylhydroquinone) were the controls.

\subsection{Quantitative Antibacterial Assay by Minimum Inhibitory Concentration (MIC) Determination}

The antimicrobial activity was assessed by the microdilution method (M07-CLSI Clinical Laboratory and Standards Institute recommendations). Two Gram-positive strains (S. aureus ATCC BAA 1026, S. aureus 1004, an MRSA phenotype) and two Gram-negative strains (E. coli ACTCC 25922; E. coli B11, ESBL phenotype) were used. The MDR strains were isolated from wound infections and characterized in the previous studies. Ethanol $50 \%$ was the control $[14,15]$.

\subsection{Solar Protection Factor (SPF) Determination-In Vitro}

The UV-VIS method was used to evaluate the in vitro SPF value in the presence of extracts, between 290-320 nm [16]. The same method determinates UVA/UVB to a maximum of $450 \mathrm{~nm}$.

\subsection{Quantification of Polyphenolic Compounds by Capillary Zone Electrophoresis}

\subsubsection{Reagents}

All standards and reagents were of analytical purity as follows: rutin trihydrate, naringenin, rhamnetin, isoquercitrin, umbelliferone, cinnamic acid, sinapic acid, chlorogenic acid, syringic acid, ferulic acid, kaempferol, luteolin, p-coumaric acid, quercetin, rozmarinic acid, caffeic acid, cichoric acid, caftaric acid, gallic acid, sodium tetraborate, sodium dodecyl sulfate, they were purchased from Sigma-Aldrich (Steinheim, Germany). Ultrapure water and 0.1 and $1 \mathrm{M}$ sodium hydroxide solutions were purchased from Agilent Technologies (Waldbron, Germany).

Methanol (Sigma, Steinheim, Germany) and solutions were filtered on 0.2- $\mu \mathrm{m}$ membranes (Millipore, Bedford, MA, USA) and degassed prior to use in an ultrasonic bath. Stock solutions for each standard were stored at $+4{ }^{\circ} \mathrm{C}$.

\subsubsection{Equipment and Method}

The Capillary Zone Electrophoresis (CZE) technique was used for the separation of bioactive compounds. The experiments were performed using an Agilent $7100 \mathrm{CE}$ instrument with a diode array detector (DAD), a CE capillary electrophoresis device (Agilent Technologies, Ratingen, Germany), and bare fused silica (ID $50 \mu \mathrm{m}, 68 \mathrm{~cm}$ effective 
length). The following parameters were maintained: Voltage $30 \mathrm{kV}$, cassette capillary temperature $30^{\circ} \mathrm{C}$, hydrodynamic injection for sample and standards ( $35 \mathrm{mbar} / 12 \mathrm{~s}$ ). The migration buffer (BGE) was $35 \mathrm{mM}$ sodium tetraborate, $0.9 \mathrm{mM}$ sodium dodecyl sulfate (SDS) at $\mathrm{pH}=9.15$. The capillary electrophoresis device was washed between migrations, with $0.1 \mathrm{M} \mathrm{NaOH}$ and water for one minute, followed by two minutes of washing with BGE. The ChemStation program was used for data interpretation. The standard and sample solutions were diluted in methanol. The identification of the compounds was realized by the addition of standards, and the retention times were compared at $\lambda=280 \mathrm{~nm}$ [8]. The linearity of the response was established for each polyphenol by building the calibration curves. All calibration curves expressed good linearity $\left(r^{2}>0.994\right)$ within the test range. Detection and quantification limits varied between $0.34-2.27 \mu \mathrm{g} \mathrm{mL}^{-1}$ and $1.02-6.89 \mu \mathrm{g} \mathrm{mL} \mathrm{m}^{-1}$ respectively.

\subsection{In Vitro Antiproliferative Assay}

The Vybrant ${ }^{\circledR}$ MTT cell proliferation test kit (Thermo Fisher Scientific, Waltham, MA, USA) was used to assess the cytotoxic effect of the extracts. The metabolic activity of HCT-8 cells (human ileocecal carcinoma-HCT-8 cell line, passage 43) was measured. The HCT-8 cells were cultivated in RPMI 1640 (Lonza, Switzerland), provided with 10\% FBS (fetal bovine serum) (Biochrom, Germany). The cultivation conditions were $37^{\circ} \mathrm{C}$ and $5 \% \mathrm{CO}_{2}$ until the cells reached a $60 \%$ confluence. A fresh medium was prepared, and extracts in three different concentrations of $10 \%, 5 \%$, and $0.1 \%$ were used. The HCT- 8 cells were washed twice with PBS (phosphate-buffered saline) after $24 \mathrm{~h}$ and incubated for $2.5 \mathrm{~h}$ with the MTT solution. After the dye had dissolved in DMSO, the 96 plates were read at $540 \mathrm{~nm}$ using Synergy HTX (BioTek, Winooski, VT, USA). Cell viability was calculated according to the formula: \% survival $=$ (average experimental absorbance/average control absorbance) $\times 100$ [17]. 50\% ethanol was the control [8].

\subsection{Statistical Analysis}

All the parameters were evaluated at least in triplicate, and the results were expressed as the mean, standard deviation (SD) values of three independent determinations. The statistical analysis and means/SD values were calculated using GraphPad Prism ${ }^{\circledR}$ version 9.1.0 (GraphPad Software, San Diego, CA, USA). For DPPH, radical scavenging activity, and reducing power, the one-way ANOVA was used, followed by a Brown-Forsythe test, while for the antiproliferative assay, we applied a two-way ANOVA test. The strength of the correlation between all parameters was obtained by calculating the Pearson correlation coefficient (r). The significance level for the calculations was $p$ express.

\section{Results}

The phytochemical analysis by CZE demonstrated the presence, in considerable quantities, of two flavonoids, Isoquercitrin and kaempferol, regardless of the analyzed banana species. The latter compound was present in a high amount in the extract of red banana peel $28.80 \pm 2.47 \mu \mathrm{g} / \mathrm{mL}$, compared to the yellow peel banana, which showed a value of $9.30 \pm 0.8 \mu \mathrm{g} / \mathrm{mL}$. Isoquercitrin had a more balanced distribution in the two extracts of $14.54 \pm 0.44 \mu \mathrm{g} / \mathrm{mL}$ in the common species, compared to $10.47 \pm 0.32 \mu \mathrm{g} / \mathrm{mL}$ in the red one. Kaempferol is a common occurrence in red products and is considered the main flavonol [18]. Isoquercitrin has been identified to have effects associated with anti-inflammatory protection and is reported as a secondary flavanol in banana extracts. It has no other in vitro/in vivo experimental data in the banana samples [19]. Other polyphenolic compounds identified in the two extracts were ferulic acid $(34.97 \pm 2.44 \mu \mathrm{g} / \mathrm{mL}$ for BP and $63.55 \pm 4.38 \mu \mathrm{g} / \mathrm{mL}$ for BPR), sinapic acid $(19.44 \pm 1.78 \mu \mathrm{g} / \mathrm{mL}$ for BP and $35.17 \pm 3.26 \mu \mathrm{g} / \mathrm{mL}$ for BPR) and quercetin $(6.14 \pm 0.65 \mu \mathrm{g} / \mathrm{mL}$ for BP and $1.14 \pm 0.05 \mu \mathrm{g} / \mathrm{mL}$ for BPR; Supplementary Figure S1).

The different numbers of asterisks represent significant statistical differences (control vs. samples; $p \leq 0.05), n=3$. 
Cytotoxicity tests have shown a dose-dependent effect on the BPR extract (Figure 1). The cytotoxic effect has not been calculated for BP, which is a factor in stimulating the proliferation of the tumor cells used in this study. The BPR extract, in a concentration of 5\%, exerts high cytotoxicity by reducing the proliferation of colon cancer cells by more than $50 \%$. These data showed that BPR has an optimal effect for inhibiting the proliferation of tumor cells when compared with the BP extract.

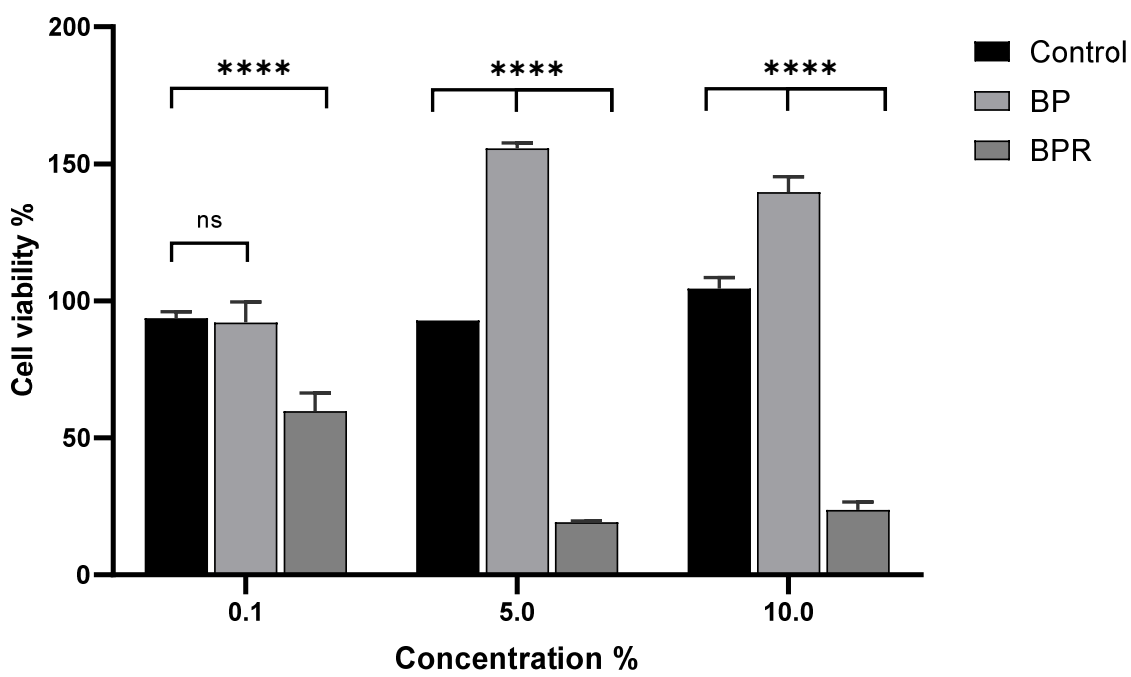

Figure 1. HCT-8 cell viability based on MTT protocol in the case of banana peel extracts. Different numbers of asterisks represent significant statistical differences ${ }^{* * * *} p<0.001$; ns-not significant), $n=3$.

Also, antimicrobial analysis has shown that it directly correlates with the antioxidant effects previously demonstrated for other functional natural products [20]. The BPR extract exerts the highest antimicrobial activity against all microbial strains with a MIC of 3.125\%. The BP sample stimulates the growth of microbial cells with a MIC of over $50 \%$ (Table 1). These results demonstrated a direct relationship between the inhibitory activity exerted by the BPR extract on both eukaryotic and prokaryotic cell proliferation. On the other hand, the BP extract has the opposite effect by stimulating the proliferation of eukaryotic and prokaryotic cells. The antagonistic effect of these two banana extracts could be associated with the variation of the chemical composition of the active compounds present in these two extracts. Along with microelements, flavonoids, phenolic compounds (galocatechin, dopamine, catecholamines), polyunsaturated fatty acids, essential amino acids, red banana peel is an important source of anthocyanins [21]. These in vitro data also show why certain natural products do not confirm, in the case of long-term administration or even a series of adverse reactions, to different population groups [16].

Table 1. MIC (\%) of plant extracts against bacterial strains.

\begin{tabular}{cccc}
\hline Samples & BPR & BP & Control \\
\hline S. aureus ATCC BAA 1026 & 3.125 & 50 & 12.5 \\
\hline S. aureus 1004 & 3.125 & 50 & 25 \\
\hline E. coli ACTCC 25922 & 3.125 & $>50$ & 12.5 \\
\hline E. coli B11 & 3.125 & $>50$ & 12.5 \\
\hline
\end{tabular}

Previous tests have been supported by an in vitro evaluation of the antioxidant potential in vitro (Figures 2 and 3). Although no significant difference was demonstrated between the two extracts, BPR had a higher potential to reduce oxidative stress in vitro. In scavenging the DPPH radical, the difference was approximately $20 \%$ for BPR and $40 \%$ for AA, 
however, it was similar to the second TBHQ control $(p \leq 0.001)$. In contrast, the reducing power of the extracts was identical to AA, but $25 \%$ lower than TBHQ (BP $-p \leq 0.01$ and $\mathrm{BPR}-p \leq 0.001)$. These data demonstrated the superior specificity of BPR compared to $\mathrm{BP}$, which was directly correlated with the cytotoxic effect (Figure 2) and phytochemical composition.

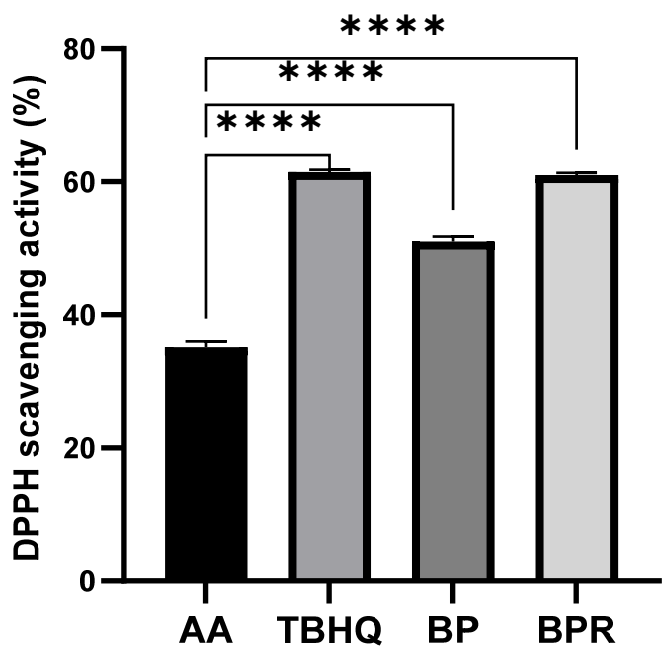

Figure 2. In vitro DPPH scavenging activity of the extracts. Different numbers of asterisks represent significant statistical differences $\left.{ }^{* * * *} p<0.001\right), n=3$.

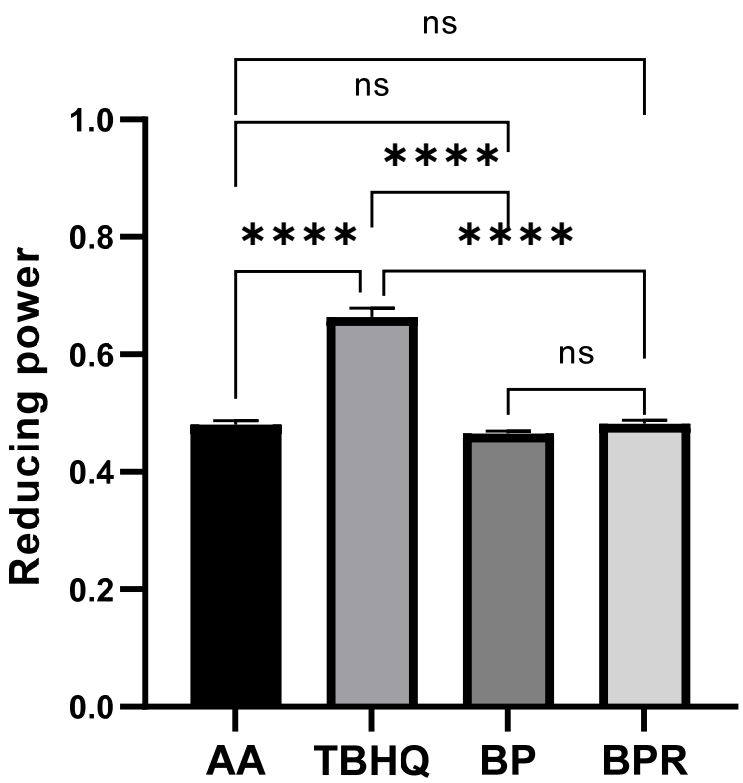

Figure 3. In vitro reducing power of the extracts. Different numbers of asterisks represent significant statistical differences (AA/TBHQ vs. samples; $p \leq 0.05$ ), $n=3$. Different numbers of asterisks represent significant statistical differences $\left({ }^{* * * *} p<0.001\right.$; ns-not significant), $n=3$.

Also, the BPR extract had a high SPF value of 0.975 . This value was similar to that obtained for the Vitis vinifera extract ([16], at approximately $310 \mathrm{~nm}$, being valid for UVB radiation. The UVA/UVB rate was 0.9 , similar to the Benitaka grape (Vitis vinifera L.) peel extract [16].

In the Pearson correlation coefficient (r), the values showed that the presence of other functional compounds was also possible, as demonstrated by the negative values of this index (Figure 4). The in vitro analysis of the extracts showed negative values compared to phenols/flavonoids or a weak correlation, as in cytotoxicity, compared to HCT-8. 


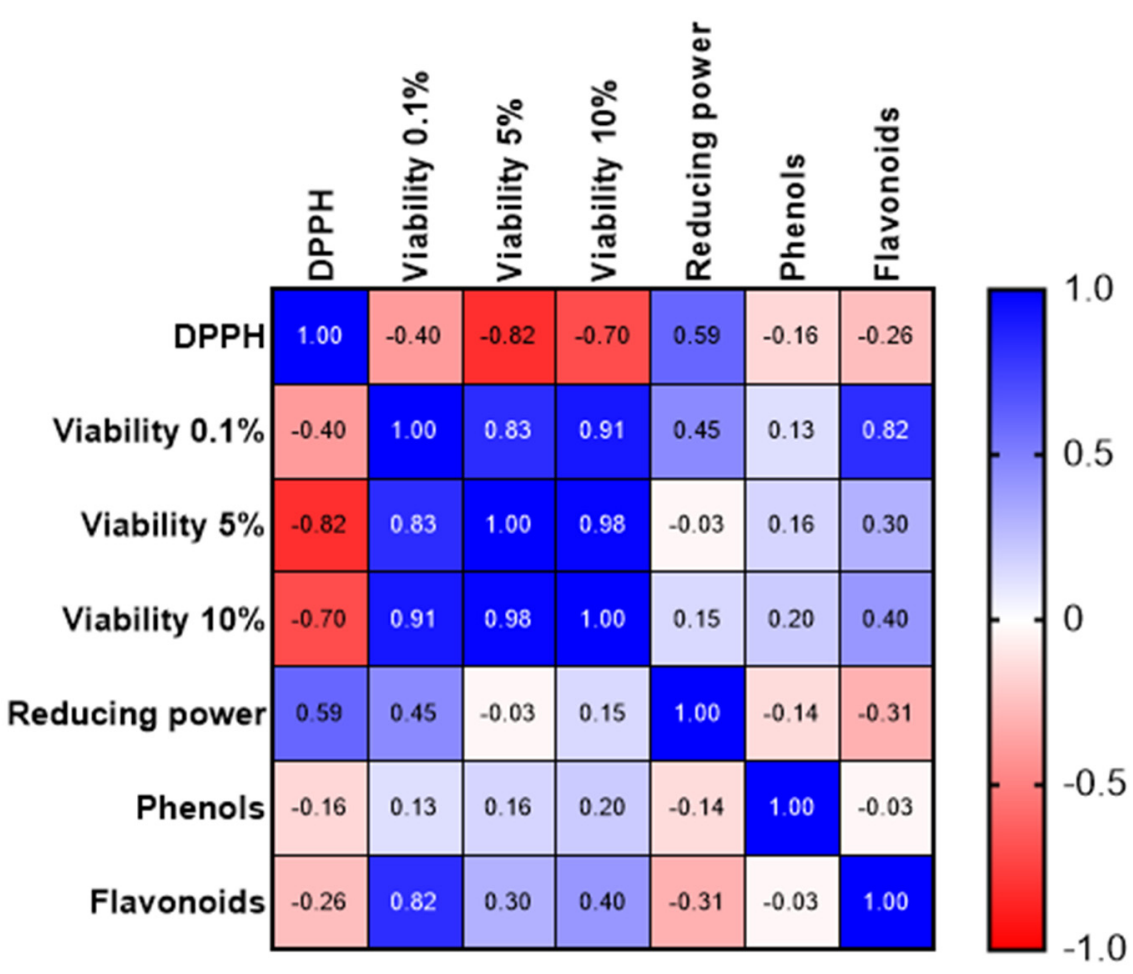

Figure 4. The Pearson-s correlation coefficient between bioactive compounds, antioxidant activity and cell viability.

The significance of the study was to demonstrate a valuable method to anticipate the commercial value of these by-products of the agricultural industry. Such studies show that the circular economy's principles yield superior natural compounds, ensuring maximum food products [22]. The correlation of the antimicrobial effect with the antioxidant and cytotoxic capacity demonstrated a new valorization possibility, for example, in controlling recurrent infections with MDR pathogenic strains. The target could be the functional product that could control microbial proliferation in hospitals [23].

Food waste valorization is a current concern, especially in emerging economies that want to increase competitiveness through efficient waste management, impacting the environment and human health. Inefficient extraction methods can slow down these targets. The use of banana peel determined and maintained an average yield of $7.5 \%(p \leq 0.05)$, a result similar to previous research using the microwave extraction method. The values differed depending on the temperature and the extraction time [24]. Differences of approximately 20\% were determined for the antiradical effect (DPPH scavenging assay, Figure 2), but not difference depending on the concentration of the reducing power (Figure 3). These differences were considered to be the result of different extraction processes that led to variations in the amount of bioactive compounds. From this, we can result in a potential negative point of the research, which led to the decrease of the extractive yield and the degree of capitalization of the substrate. The role of the extractive process was best seen in the case of BPR where the in vitro values of antioxidant protection had results close to $\mathrm{BP}$, which has a direct result on the protection against stress caused by UV. The presence of a high number of phenolic compounds does not mean a direct effect on antioxidant protection. The effect was determined by the high number of bioactive molecules that can provide protection in different ways and act convergently.

In addition, the cytotoxic effect was correlated in previous studies with an antimicrobial effect [25], which was demonstrated in the case of BPR extract compared to BP. This relationship was present in the current study, confirming the aforementioned studies. In addition to the cytotoxic effect, an antiviral effect could also be demonstrated [26]. Analyzing the results of the two studies, it was found that the concentration of bioactive compounds 
differs from one species to another, depending on the composition and geographical area of origin. However, the pattern consists of the same main compounds, on which the concentration depends.

Banana peel is a valuable raw material that can be exploited efficiently to alleviate health problems associated with oxidative stress. The recovery of the bioactive components of this food waste supports their use in obtaining cosmetics with antioxidant and antimicrobial UV protection effects, by reducing the presence of free radicals and acute inflammatory proliferation in the dermis [27].

\section{Conclusions}

In conclusion, the results obtained for red banana peels extract (antioxidant activity, antimicrobial effect, and cytotoxic activity on tumor cells) showed a higher biological value than that of the yellow banana peel extract. The highest polyphenol content in kaempferol and its superior antioxidant capacity supported the high antimicrobial activity against pathogenic bacterial strains. In the circular economy, this is a source of biologically active compounds that can be recovered, demonstrating the added value of food waste products. Future optimization studies will confirm that traditional extractive processes can also increase the number of bioactive compounds. The temperature and correlation of the applied methods have demonstrated the ability of banana peel extracts to combat oxidative stress, being suitable for biopharmaceutical uses or to enrich UV protection creams.

Supplementary Materials: The following supporting information can be downloaded at: https: / / www.mdpi.com/article/10.3390/pr10020248/s1, Figure S1: Separation of polyphenols by CZE from BP and BPR extracts. The extracts were concentrated 4 times for BP and 2 times for BPR. Standards: 1-rutin; 2-naringenin; 3-rhamnetin; 4-isoquercitrin; 5-umbelliferone; 6-cinnamic acid; 7—sinapic acid; 8—chlorogenic acid, 9—syringic acid; 10—ferulic acid; 11—kaempferol; 12 luteolin; 13-p-coumaric acid; 14-quercetin; 15-rozmarinic acid, 16-caffeic acid; 17—cichoric acid; 18-caftaric acid; 19-gallic acid.

Author Contributions: E.V. planned the researchers F.G. and I.A. analyzed the data. I.A., E.V. and F.G. wrote the paper. All authors debated and made approved the results. All authors have to accept the manuscript's submitted version. All authors have read and agreed to the published version of the manuscript.

Funding: This research received no external funding.

Institutional Review Board Statement: Not applicable.

Informed Consent Statement: Not applicable.

Data Availability Statement: Graphical Abstract is created with BioRender.com (accessed on 26 January 2022).

Acknowledgments: We acknowledge the financial support of project no. 327/390003/06-11-2020, SMIS code: 126867, "Strengthening the research capacity for ecosystem and biodiversity at the University of Bucharest through e-science and technology-Lifewatch Romania"; co-financed under Regional Development Fund (ERDF), Competitiveness Operational Programme.

Conflicts of Interest: The authors declare no conflict of interest.

\section{References}

1. Manzoor, A.; Ahmad, S. Banana Peel: Characteristics and Consideration of Its Extract for Use in Meat Products Preservation: A Review. ACS Food Sci. Technol. 2021, 9, 1492-1506. [CrossRef]

2. Jin, G.H.; Liu, Y.; Jin, S.Z.; Liu, X.D.; Liu, S.Z. UVB induced oxidative stress in human keratinocytes and protective effect of antioxidant agents. Radiat. Environ. Biophys. 2007, 46, 61-68. [CrossRef]

3. Sánchez-Marzo, N.; Pérez-Sánchez, A.; Castillo, J.; Herranz-López, M.; Barrajón-Catalán, E.; Micol, V. Oxidative Stress and DNA damage in human keratinocytes by citrus and olive formulations. Free Radic. Biol. Med. 2017, 108, S82. [CrossRef]

4. El Barnossi, A.; Moussaid, F.; Iraqi Housseini, A. Tangerine, banana and pomegranate peels valorisation for sustainable environment: A review. Biotechnol. Rep. 2020, 29, e00574. [CrossRef] [PubMed] 
5. $\quad$ Rivadeneira, J.P.; Wu, T.; Ybanez, Q.; Dorado, A.A.; Migo, V.P.; Nayve, F.R.P., Jr.; Castillo-Israel, K.A.T. Microwave-Assisted Extraction of Pectin from "Saba" Banana Peel Waste: Optimization, Characterization, and Rheology Study. Int. J. Food Sci. 2020, 2020, 8879425. [CrossRef]

6. Jamal, P.; Saheed, O.K.; Alam, Z. Bio-Valorization Potential of Banana Peels (Musa sapientum): An Overview. Asian J. Biotechnol. 2012, 4, 1-14. [CrossRef]

7. Chueh, C.C.; Lin, L.J.; Lin, W.C.; Huang, S.H.; Jan, M.S.; Chang, S.C.; Chung, W.S.; Lee, T. Antioxidant capacity of banana peel and its modulation of Nrf2-ARE associated gene expression in broiler chickens. Ital. J. Anim. Sci. 2019, 18, 1394-1403. [CrossRef]

8. Vamanu, E.; Gatea, F.; Pelinescu, D.R. Bioavailability and Bioactivities of Polyphenols Eco Extracts from Coffee Grounds after In Vitro Digestion. Foods 2020, 9, 1281. [CrossRef]

9. Abreu-Naranjo, R.; Paredes-Moreta, J.G.; Granda-Albuja, G.; Iturralde, G.; González-Paramás, A.M.; Alvarez-Suarez, J.M. Bioactive compounds, phenolic profile, antioxidant capacity and effectiveness against lipid peroxidation of cell membranes of Mauritia flexuosa L. fruit extracts from three biomes in the Ecuadorian Amazon. Heliyon 2020, 6, e05211. [CrossRef]

10. Gomes, C.; Silva, A.C.; Marques, A.C.; Sousa Lobo, J.; Amaral, M.H. Biotechnology Applied to Cosmetics and Aesthetic Medicines. Cosmetics 2020, 7, 33. [CrossRef]

11. Dabulici, C.M.; Sârbu, I.; Vamanu, E. The Bioactive Potential of Functional Products and Bioavailability of Phenolic Compounds. Foods 2020, 9, 953. [CrossRef] [PubMed]

12. Yang, X.N.; Kang, S.C. In vitro antioxidant activity of the water and ethanol extracts of Forsythia koreana flowers. Nat. Prod. Res. 2012, 26, 375-379. [CrossRef] [PubMed]

13. Idamokoro, E.M.; Masika, P.J.; Muchenje, V. A Report on the In Vitro Antioxidant Properties of Vachellia karroo Leaf Extract: A Plant Widely Grazed by Goats in the Central Eastern Cape of South Africa. Sustainability 2017, 9, 164. [CrossRef]

14. Mihai, M.M.; Holban, A.M.; Giurcăneanu, C.; Popa, L.G.; Buzea, M.; Filipov, M.; Lazăr, V.; Chifiriuc, M.C.; Popa, M.I. Identification and phenotypic characterization of the most frequent bacterial etiologies in chronic skin ulcers. Rom. J. Morphol. Embryol. 2014, $55,1401-1408$

15. Sarbu, I.; Vassu, T.; Chifiriuc, M.C.; Bucur, M.; Stoica, I.; Stefana, P.; Rusu, E. Assessment the Activity of Some Enzymes and Antibiotic Substances Sensitivity on Pathogenic Bacteria Species. Rev. Chim. 2017, 68, 3015-3021. [CrossRef]

16. Cefali, L.C.; Ataide, J.A.; Fernandes, A.R.; Sanchez-Lopez, E.; Sousa, I.M.d.O.; Figueiredo, M.C.; Ruiz, A.L.T.G.; Foglio, M.A.; Mazzola, P.G.; Souto, E.B. Evaluation of In Vitro Solar Protection Factor (SPF), Antioxidant Activity, and Cell Viability of Mixed Vegetable Extracts from Dirmophandra mollis Benth, Ginkgo biloba L., Ruta graveolens L., and Vitis vinifera L. Plants 2019, 8, 453. [CrossRef]

17. Prochor, P.; Mierzejewska, Z.A. Influence of the Surface Roughness of PEEK GRF30 and Ti6Al4V SLM on the Viability of Primary Human Osteoblasts Determined by the MTT Test. Materials 2019, 12, 4189. [CrossRef]

18. Cid-Ortega, S.; Monroy-Rivera, J.A. Extraction of Kaempferol and Its Glycosides Using Supercritical Fluids from Plant Sources: A Review. Food Technol. Biotechnol. 2018, 56, 480-493. [CrossRef]

19. Yun, J.E.; Lee, H.; Ko, H.J.; Woo, E.R.; Lee, D.G. Fungicidal effect of isoquercitrin via inducing membrane disturbance. Biochim. Biophys. Acta (BBA)—Rev. Biomembr. 2015, 1848, 695-701. [CrossRef]

20. Ekor, M. The growing use of herbal medicines: Issues relating to adverse reactions and challenges in monitoring safety. Front. Pharmacol. 2014, 4, 177. [CrossRef]

21. Fu, X.; Cheng, S.; Liao, Y.; Huang, B.; Du, B.; Zeng, W.; Jiang, Y.; Duan, X.; Yang, Z. Comparative analysis of pigments in red and yellow banana fruit. Food Chem. 2018, 239, 1009-1018. [CrossRef] [PubMed]

22. Barone, A.S.; Matheus, J.R.V.; de Souza, T.S.P.; Moreira, R.F.A.; Fai, A.E.C. Green-based active packaging: Opportunities beyond COVID-19, food applications, and perspectives in circular economy-A brief review. Compr. Rev. Food Sci. Food Saf. 2021, 20, 4881-4905. [CrossRef] [PubMed]

23. Vamanu, E.; Dinu, L.-D.; Luntraru, C.M.; Suciu, A. In Vitro Coliform Resistance to Bioactive Compounds in Urinary Infection, Assessed in a Lab Catheterization Model. Appl. Sci. 2021, 11, 4315. [CrossRef]

24. Anal, A.K.; Jaisanti, S.; Noomhorm, A. Enhanced yield of phenolic extracts from banana peels (Musa acuminata Colla AAA) and cinnamon barks (Cinnamomum varum) and their antioxidative potentials in fish oil. J. Food Sci. Technol. 2014, 51, 2632-2639. [CrossRef]

25. Al-Mqbali, L.R.A.; Hossain, M.A. Cytotoxic and antimicrobial potential of different varieties of ripe banana used traditionally to treat ulcers. Toxicol. Rep. 2019, 6, 1086-1090. [CrossRef]

26. Panda, S.K.; Castro, A.; Jouneghani, R.S.; Leyssen, P.; Neyts, J.; Swennen, R.; Luyten, W. Antiviral and Cytotoxic Activity of Different Plant Parts of Banana (Musa spp.). Viruses 2020, 12, 549. [CrossRef]

27. Arraibi, A.A.; Liberal, Â.; Dias, M.I.; Alves, M.J.; Ferreira, I.C.F.R.; Barros, L.; Barreira, J.C.M. Chemical and Bioactive Characterization of Spanish and Belgian Apple Pomace for Its Potential Use as a Novel Dermocosmetic Formulation. Foods 2021, 10, 1949. [CrossRef] 